\title{
THE IMPACT OF THE CORONAVIRUS PANDEMIC ON THE FORMS AND STRUCTURE OF EMPLOYMENT
}

\author{
JOSEPH ARCHVADZE \\ Doctor of Economics, Professor \\ Kutaisi University, Georgia \\ daswreba@yahoo.com
}

Abstract. The coronavirus pandemic almost immediately led to a global narrowing of the global economy, a sharp reduction in aggregate supply and demand. The decline in production was especially felt in the second quarter of 2020 , when the recession in most countries of the world had a double-digit value. According to IMF forecasts, in general, the economy in developed countries, even in 2021, will not reach the level of 2019.

The global economic downturn is accompanied by a massive reduction in jobs, rising unemployment, especially in industries that are focused on foreign markets and serving foreign consumers (export production, reception and service of foreign tourists, international transportation, etc.).

The economic crisis caused by the coronavirus also hit global economic and technological ties, led to their widespread fail in many geographical points of the planet, and increased the risk of fragmentation and regionalization of the global market.

All this was adequately reflected in change of global demand for labor, in a significant transformation of the structure, size and location of employment, and the state of the labor market as a whole.

At the same time, the global crisis did not equally affect the level of employment in different types of activity, the formation of demand for labor, the labor market as a whole; the structure of jobs and employment in individual professions, instead of a proportional change, was uneven - mainly in an asymmetric form.

\section{KEYWORDS: GLOBAL PANDEMIC, LABOR MARKET, LABOR FORCE, WORKPLACE, UNEMPLOYMENT RATE.}

For citation: Arhvadze, J., (2020). The Impact of the Coronavirus Pandemic on the Forms and Structure of Employment. Globalization and Business, 10. 117-120. https://doi.org/10.35945/gb.2020.10.014

Amid the global crisis, there has been a sharp decline in aggregate demand for labor - similar to that which occurred in the early nineteenth century in England after the invention of looms - among weavers or in the early twentieth century in the United States and some other countries - among industrial workers, as the mass introduction of advanced technical, automatic means of production. Due to extraordinary circumstances, because the crisis itself is of non-economic origin, measures against it are often ineffective, and forecasts of its course and consequences are hardly predictable. Therefore, international organizations (UN, ILO) forecast for job cuts in the world several times changed upward. - from 25 million in mid-March 2020 (United Nations...,2020) to 195 million in the first half of April (Belyakov, 2020) and up to 305 million. By the end of April (Due to the coronavirus, 2020), which, according to our calculations, accounts for 9.2 percent of the total number of people employed in the world. According to later ILO estimates, in the second quarter of 2020, the loss of working hours worldwide amounted to $14 \%$, equivalent to 400 million jobs.

Due to the coronavirus, the economic recession of the world economy will reduce the current income of almost 2 billion people - $1 / 4$ of the worldss population, and the temporary, full or partial closure of production will affect $4 / 5$ of those employed in the global economy.

In view of the high correlation between the production of goods and the availability of jobs, on the other hand, during the coronavirus pandemic and in the post-pandemic period, the aggregate demand for labor will decrease, competition in the labor market, unemployment will increase, the number of people wishing to take every vacant place.

At the same time, the decline in aggregate demand for labor is unevenly reflected in different professions and activities.

Radical reformatting of the labor market and, accordingly, changes in the sphere of employment in connection with new social challenges that have arisen can be divided into two groups:

a) Reduction in the absolute number of employed mainly in the medium and small business, self-employed and employed, especially in the service sector, which turned out to be the most vulnerable area under the onslaught of the coronavirus pandemic;

b) Instead of dismissal of employees - reduction of salaries and addition to the salaries of employees - mainly in the field of large business, in certain sectors of services and in the public (state) sector. 
Which industries are more susceptible to reduction in the number of employees?

Traditionally, the middle class, who are tied to small business and individual entrepreneurship, will not be lucky most of all. The number of small enterprises will sharply decrease, and their owners will have to "move» to the ranks of the precariat. The first sprouts of such a reduction may be a multiple drop in a newly registered company, for example, according to the Georgian Statistical Office, in April 2020, the number of newly registered companies decreased by almost 10 times compared to the corresponding month of 2019, and in May, by almost 3 times.

The number of employed people in the economy decreased (is reduced) both by functional attribute (by industry) and by type of economic activity (occupation), especially in the informal (shadow) sector.

In particular, the following sectors were particularly affected by the reduction of jobs on a functional basis: foreign trade, aviation (employment related to the operation and maintenance of civil aviation) and road transport, as well as industries focused on leisure, entertainment and recreation: tourism (travel agents, guides), hotels and restaurants (waiters and cooks), beauty salons, fitness (representatives of the fitness industry, instructors), advertising, events, sports, theater, cinema, etc.

Job cuts are foreseen in areas that are more "office career counseling" (marketing, accounting, advertising, PR, human resources, law, junior employees of specialized departments, analysts, event managers, managers, secretaries, administrators, security guards, cleaners, midlevel manager of commercial banks, realtors, etc.), which will lead to a sharp reduction in office space and a massive movement of employees in the so-called home offices and virtual substitution of participation in any meetings and presentations. The tsunami of reduction will cover representatives of such professions as translators, teachers and tutors; Printing industry workers will also be at risk - firstly, print media for years, increasingly giving way to electronic media and the Internet, and secondly, business representatives and private customers will try to optimize their own costs and are actively moving to more economical electronic products.

In connection with the transition to the aforementioned new progressive forms of organizing trade and the establishment of additional, higher social and hygienic standards, by 2022, it is predicted that every fifth mall (hypermarket) will be closed just in the United States. According to the fact that over the past decade in this country, the number of large chain stores and shopping centers that have closed in average annual terms has increased from 4.4 thousand to 10.6 thousand (Bovt, 2020). This process, in turn, pushes shopping centers to transform into family leisure centers, food courts and coworking. Accordingly, as the number of shopping centers decreases sharply, traditional e-commerce trade will be supplanted. For traditional trade, which is gradually disappearing along with the era, only separate niches remain in the form of expensive boutiques and supermarkets.
The supply of goods on pre-orders will increase sharply. Nearby is the time when, to avoid queues and taking into account the requirements of security and social distance, shopping centers will switch to non-contact shopping where people will arrive at a predetermined time using virtual mirrors and virtual fitting rooms for each item in 3D format virtually, Without physical contact, they will try on and pick up the chosen clothes. The indicated technologies will help designers to create virtual models that customers will become familiar with, try on and order online - and only after that they will be physically tailored and delivered to consumers. Technical progress and technologies make it possible, not in the distant future, but already now, to be widely used, digitalization of the system of sizes of clothes and shoes is widespread.

In general, the reduction in many areas and activities will be significant. However, for certain types of activities, the volume of production and, accordingly, the number of employed, jobs not only not will decrease, but also will increase.

Instead of losses, they will be focused on making a profit (with preserving jobs in comparison with the parameters of the "pre-coronavirus period") those types of activities that are the production of food products and, in general, to satisfy the primary needs of the population (for example, the production and sale of medical items, pharmaceuticals, for the primary hygiene needs of the population, as well as the production of masks, sanitary devices, etc.), local trade (especially home delivery services for food and finished products), online leisure, communication, electrical communication, in general - to meet the needs and demand of the domestic consumer, to saturate the local market with local products.

Definitely, the number of jobs in the fields of security and public order, information technology and their maintenance, logistics and digitization, in agriculture, food and processing industries will increase.

At the same time, the large-scale production of tests to determine coronavirus, and later the introduction of the corresponding vaccine, will cause a powerful development of biotechnology-related industries, with a significant increase in the number of employees in them.

Demand for couriers and for persons providing the delivery of food products and other goods will increase sharply. - Although in the post-pandemic period such demand will slightly decrease compared to the pandemic period, nevertheless, their number will significantly exceed the employment level of the pre-coronavirus period.

Instead of single cases, handicraft will take on a mass character - everything that is created by skilled people, craftsmen, and this area, specializing mainly in the production of goods of limited consumption and luxury in recent decades, will "decline" and rightly regain its democratic status.

At the same time, regardless of the circumstances, the labor market will remain stable in demand for representatives of contact specialties from the face-to-face category, which, over time, will even increase - with a high correlation with the growth of incomes and welfare of the population. What will such a reformatting of the labor market bring? 
In general, the capacity of the labor market will be largely determined, on the one hand, by the aspects of organization and structure, production safety, and, on the other hand, by the rates of recovery of individual sectors and segments of the economy after the crisis and the growth of solvent demand of the population. Nevertheless, to which we can say with certainty, in the foreseeable future, the labor market will be relatively limited, and not only the number of unemployed will change significantly, but also the quality of the workforce will increase (including through greater investment by households in the education of family members, compared with investments in tangible assets), and competition for each workplace, as mentioned above, will definitely increase.

Due to the reduction in global demand, the process of reducing jobs, staffing units will take place in the form of a fall in salaries, reduction of bonus programs, and in general - significant cost savings (lower rents, a sharp reduction in maintenance staff - secretaries, security personnel, drivers, etc.). p.) - the office contingent will at least be halved (although some experts do not exclude a more radical reduction in their numbers (Brodnikov, 2020)), which will actually put an end to the so-called last-decade "Office plankton.» This will give firms the opportunity to save not only on the costs of maintaining their offices, but also achieve significant savings in salaries, not only due to a reduction in the number of employees, but also in the low-paid contingent involved from remote regions of the world.

Moreover, instead of traditional offices, the era of flexible offices is already coming - smart offices, which will operate in a service format and in which it will be possible to reserve a workspace for a certain time (for several days or even for several hours), and not necessarily in one and the same space. Compared to a regular office, in smart offices, a certain space will provide services to 1.5-2.0 times as many employees. - Moreover, such meetings will complement the remote work at home, which will take more than half of the working time. Accordingly, the desktop in smart offices will become truly working and will no longer be a training ground for demonstrating personal items, souvenirs and pictures of family members, which can often be seen in "traditional» offices.

In view of these reasons, as well as the widespread distribution of online work, there will be a sharp decline in demand for office and retail space. In particular, savings on retail space and partly on sellers will enable firms to save 20-30 percent of costs, even with a sharp increase in the home delivery system. Reformatting the labor market and the introduction of new forms and methods of activity will significantly change not only the format of production, distribution and consumption of material goods, but also the service segment.

Here they will have practically the effect of discovering the New World of novelty in the medical field, which will not only submit to the latest achievements in science, treatment and pharmacy, but will also be based on a more humane public morality. In particular, areas and scales of public responsibility for the health and life of citizens will increase. Responsibility and state monitoring for the health of citizens, instead of the current segmented nature, will become systemic. Accordingly, early diagnosis will become almost universal.

Over time, it will become possible with the help of thermal screening to identify the main risk factors for human health and to implement timely preventive measures based on them. The financial expression of this change will be that state (essentially charitable) medicine will cover the costs of healthcare, diagnosis, prevention and treatment. Private insurance medicine, which until now carried out selective care (depending on the financial condition of the clients), as usual, will be left with the possibility of plastic and aesthetic medicine, the failure of which will not carry a high risk to the life and health of the persons concerned.

Taking into account these factors, the number of people employed in the healthcare sector is increasing significantly, as was already noted above, both in the medical industry itself and in the areas of pharmacy, production and supply of medical equipment, logistic. In the world, hundreds of thousands of people will be busy with the control of those who are infected and who are in contact with them. The multibillion-dollar "corona business" industry will emerge.

\section{CONCLUSION}

The fact that the above tectonic shifts in the labor market, by the tsunami effect, will have a great impact on all spheres of public life. High probability, they will contribute to the formation of a completely new structure of social relations. The main and significant result in labor relations in the post-coronavirus period will be that only the results of labor will fall under the control of the employer - it will not matter where and how the time will be spent on their achievement. Accordingly, there will be an exemption from past fetishes such as the work week and work day. Gradually, the boundaries between the times of leisure and work of a person will be erased. - Many have already felt this erasure during the time of remote employment at home. - Now work and weekends and holidays, as well as in the evening, have become offended phenomena; the same can be said about free time.

We get virtual, new, more rational forms of not only employment, but also relaxation. - Because of this, lovers of feasts with many participants will have to radically change the format of these events in the direction of reducing the number of participants.

For remote workers, the birth of children and their upbringing will no longer be an obstacle to professional career growth.

At the same time, in the context of reduced mobility, migration and tourism, there will be a sharp reduction in the number of labor migrants and expats and the volume of their transaction addressed to their families left behind, which will especially affect the population and economies of developing countries. - On a global scale, the ratio of gross volume of remittances to world GDP is less than 1 per cent, while in Georgia - as much as 10 times more - 8.9 per cent (data for 2019). As the intensity of interstate labor migration decreases 
somewhat, interregional and intersectoral mobility within individual countries will increase.

In general, if we put on the one side of the scale the number of cut jobs in individual sectors of the economy, and on the other side - their growth in other sectors, based on the current sectoral structure of employment, the first will outweigh the second more than twice.

Naturally, these assumptions are based on the current level of development of productive forces and on the prevailing moral and subculture of society, on global processes in the world economy, as well as on the balance of interests and the "temperature" of the relationship between large states. And since these factors are subject to change, it is possible that over time, the above assumptions in certain areas will be subject to certain corrections and will be enriched with additional features.

\section{REFERENCES}

United Nations Forecasts 25 Million Job Losses Worldwide Due To Coronavirus (2020).

https://covid19.who.int/?gclid=CjwKCAiAwrf-BRA9EiwAUWwKXvyOdqfchK_6NBeDQ-YoW1JwxaZSIWsrFP8v0UCCynQIRTh14

YDLshoCuesQAvD_BwE

Belyakov, E. (2020). Why coronavirus hits the poor harder than the rich. - "KP", 04/13/2020.(in Russian)

Due to the coronavirus, by the middle of the year 305 million jobs will be lost (2020). - rambler.ru, 05/01/2020, -

Labor force, total. - https://data.worldbank.org/indicator/SL.TLF.TOTL.IN 30.

Unemployment, total. - https://data.worldbank.org/indicator/SL.UEM.TOTL.ZS.

The pandemic has deprived more than a third of the worldıs population (2020). - Nezavisimaya Gazeta, 04/21/2020. (in Russian) Named the profession, which increased the number of vacancies (2020). - Russian newspaper, April 4, 2020. (in Russian).

Bovt, G. (2020). Quarantine Paradise (2020). Newspaper.ru, 05.25.2020. (in Russian).

Kozhukhov, S. (2020). Not exciting: Coronavirus hit prostitution. Sexual services revenue fell 80\% due to coronavirus (2020). - gazeta.ru, 04/15/2020. (in Russian).

Brodnikov, M. (2020). Offices after the pandemic: where the white-collar workers will return from quarantine (2020). rbc.ru, 05/05/2020. (in Russian).

Ryder, G. (2020). Our task is to build a better world than before the crisi. On the loss of the global labor market due to the pandemic and the prospects for its recovery - Izvestia, July 6, 2020. (in Russian). 